\title{
APRESENTAÇÃO \\ Arte em tempos de pandemia: rotas para análises
}

\section{Art in pandemic times: routes for analises}

Como produzir, fazer circular e proporcionar a recepção de trabalhos de arte em tempos de pandemia? Esta é a pergunta chave deste número temático. A partir da suspensão das atividades de centros culturais, casas de espetáculos, cinemas, teatros, museus e toda sorte de equipamentos culturais voltados à circulação de trabalhos artísticos em virtude da disseminação do, já não tão novo, coronavírus, que tem ceifado vidas ao redor do mundo, este dossiê buscou reunir estudos que debatem os efeitos do isolamento social, da gestão da crise em termos políticos e econômicos, bem como as reações do setor artístico e cultural.

\section{Brasil, o país em que arte e cultura viraram sinônimo de crise}

Em março de 2021, passado um ano dos primeiros casos de contaminação comunitária pela Covid-19 no Brasil, o país começa a contar os efeitos, ainda imprevisíveis, da pandemia que assola o mundo. Os dados do IBGE apontam que, além das vidas perdidas, o impacto sobre a economia nacional tem sido devastador. A queda de 4,1\% do PIB $^{1}$, no ano de 2020 , que marcou o início da pandemia, ainda que inferior às projeções mais pessimistas, oculta uma variação mais profunda, acentuada pela desvalorização da moeda brasileira. Segundo critérios do FMI, a queda levou o país à $12^{\mathrm{a}}$ posição no ranking das maiores economias do mundo. O cenário estimado por agências de risco e instituições financeiras, foi amplamente divulgado na imprensa ${ }^{2}$.

1. IBGE. Painel de indicadores. Disponível em: <https://www.ibge.gov.br/indicadores>. Acesso: 28 de mar. 2021.

2. Durão, Mariana. País deixa grupo das dez maiores economias. São Paulo: O Estado de São Paulo, 04 
Do ponto de vista da renda das famílias, efeitos dramáticos também podem ser computados em números. Os índices de desemprego alcançaram a média inédita de 13,5\%. A taxa de desocupação no último trimestre de 2020 alcançou 13,9\%. Aos 13,9 milhões de desempregados se somavam em dezembro daquele ano 5,5 milhões de desalentados e 31,2 milhões de subocupados. Mesmo as taxas de informalidade caíram de 41,1\% em 2019 para 38,7\% em 2020. Nas médias anuais, o nível da ocupação ficou em 49,4\% em 2020, menos de $50 \%$ da população economicamente ativa ${ }^{3}$.

Ainda segundo a $\mathrm{PNAD}^{4}$, a renda domiciliar per capita caiu $4,1 \%$, alcançando o patamar de $\mathrm{R} \$ 1.380,00$ mensais, num ano em que a inflação medida pelo IPCA, a despeito dos sucessivos impactos sobre a demanda, subiu 4,52\% O retrato da crise é devastador. Além de mais de 300.000 mortes $^{6}$, resultantes das medidas vacilantes de distanciamento social e grave incentivo à desinformação, a economia também agoniza.

No entanto, o debate proposto neste número temático demonstra, especificamente, naqueles textos que tratam do campo artístico e cultural brasileiro, que a crise não se iniciou em março de 2020 (quando se decretou paralisação de atividades que causam aglomeração em muitos estados) por conta do vírus, mas data de um longo histórico de políticas públicas para o setor cultural. Conforme

de mar. 2021. Disponível em: <https://economia.estadao.com.br/noticias/geral,brasil-deixa-ranking-das-10-maiores-economias-apos-queda-de-4-1-do-pib,70003634630>. Acesso: 28 de mar. 2021. 3. IBGE. Pesquisa Nacional por Amostra de Domicílios Contínua - PNAD CONTíNUA - Principais destaques da evolução do mercado de trabalho no Brasil 2012-2020. Disponível em: $<$ https://ftp.ibge.gov. br/Trabalho_e_Rendimento/Pesquisa_Nacional_por_Amostra_de_Domicilios_continua/Principais_ destaques_PNAD_continua/2012_2020/PNAD_continua_retrospectiva_2012_2020.pdf $>$. Acesso: 28 de mar. 2021.

4. Idem.

5. IBGE. Painel de indicadores. Disponível em: <https://www.ibge.gov.br/indicadores >. Acesso: 28 de mar. 2021.

6. De acordo com o projeto Worldometer que compila dados de diversas agências certificadas, o índice de 300.000 mortes teria sido alcançado em 24 de março de 2021. Disponível em: <https:// www.worldometers.info/coronavirus/country/brazil/>. Acesso: 28 de mar. 2021. 
argumentamos em outras ocasiões, as tensões entre arte e política vêm, há muito, constituindo eixo central nos desdobramentos da produção de cultura e têm efeitos concretos nas disputas pelo financiamento da área (sANT'ANNA, MARCondes, ACCORsi, 2017). Também o artigo de Alexandre Barbalho (2018), intitulado "Política Cultural em Tempo de Crise: o Ministério da Cultura no Governo Temer", contribui para repensar a dissolução das políticas para a cultura como processo de longa duração. Se entre 2003 e 2009, o orçamento do Ministério da Cultura cresceu 142\%, ampliando a participação no PIв de 0,2 para quase 1\% (BUENO, SANT'ANNA, DABUL, 2018), em anos recentes alterações profundas têm se estabelecido.

Se Barbalho (2018) nos lembra que, ainda em 2011, Ana de Hollanda foi nomeada Ministra da Cultura, tendo sido afastada do cargo no ano seguinte "já com déficit de representatividade e de sua legitimidade" (BARBALHO, 2018, p. 246), após o impeachment de Dilma Rousseff e a tomada do poder executivo federal por seu vice, Michel Temer, o setor viu a crise se acirrar. Basta que lembremos da tentativa de enfraquecimento do setor com o fim do Minc ainda em 2016, que foi revogado pelo governo interino graças à mobilização popular e ação em movimento que se espalhou pelo país de ocupação dos prédios do hoje finado Ministério (BARbalho, 2018, p. 254).

É importante também lembrar, que no contexto de mobilização para o pleito eleitoral de 2017, não foram poucos os ataques que o campo da arte e da cultura recebeu, com práticas de censura e de encerramento de exposições por conta de mobilizações políticas e econômicas que contribuíram para a vitória do projeto de poder que hoje está em curso e que retoma princípios gestados em acordo com a "colonialidade do poder" (QUiJAno, 2009). Em contraposição às pautas identitárias que vinham se difundido no decênio anterior, voltam a grassar as opressões e violências desferidas contra populações minoritárias em termos de poder.

Assim, enquanto projeto de gestão para o setor artístico e cultural, o que se teve foi o seu desmonte. É sintomático o fim do Ministério da Cultura, transformado em Secretaria Especial de Cultura, primeiro vinculada ao Ministério da Cidadania e, até o momento, ao de Ministério do Turismo. Fato é que a 
perda do status de Ministério para o de Secretaria informa sobre como os atuais governantes do país entendem o papel da cultura: atribuição menor do Estado ou inimiga a ser contida. Afinal, não esqueçamos os ataques ao setor, especialmente, por parte de políticos no pleito de 2017 quando, por exemplo, a exposição "Queermuseu - Cartografias da diferença na arte brasileira" sofreu inúmeros ataques. Na ocasião, seu curador, Gaudêncio Fidelis, foi até mesmo convocado para dar explicações na Comissão Parlamentar de Inquérito (CPI) dos Maus-Tratos contra Crianças e Adolescentes, do Senado Federal, então presidida por Magno Malta, à época senador pelo Partido Liberal (PL). Mas este foi apenas o prenúncio de mais um capítulo das batalhas a serem enfrentadas pelo setor artístico e cultural brasileiro.

Destarte, a história da gestão da Secretaria Especial de Cultura do atual governo federal também soma controvérsias com gestores que não atendiam às mobilizações e expectativas do setor. Em dois anos, a Secretaria já foi gerida por cinco secretários e dois interinos: Henrique Pires, José Paulo Martins (interino), Roberto Braga, Roberto Alvim, José Paulo Martins (interino), Regina Duarte e Mário Frias (atual ocupante do cargo). No ano marcado pelo início da pandemia de Covid-19, a Secretaria passou de mãos por três vezes, contando com personagens sem representatividade e legitimidade junto ao setor artístico e cultural do país. Valendo a rememoração de alguns dos escândalos causados pelos personagens colocados à frente da pasta, por exemplo, quando Roberto Alvim ao lançar um programa de incentivo à cultura, o fez em um vídeo que trazia nítidas referências ao nazismo, ou, ainda, quando Regina Duarte, em entrevista sobre sua gestão, minimizou as ações da Ditadura civil-militar que tomou o Brasil entre 1964 e 1985. Chegando ao momento em que Mário Frias entra no comando da pasta sem um currículo que demonstre sua capacidade para gerir o campo artístico e cultural nacional.

Porém, o setor que já enfrentava crises passou por provações ainda maiores nos últimos anos. $\mathrm{O}$ impacto gerado mundo afora pela disseminação da pandemia de Covid-19 e adoção (por parte de governos estaduais e municipais, lembremos) de medidas de isolamento social que, se por um lado, salvam vidas, por outro, vêm contribuindo, no Brasil, para o agravamento da crise na 
cultura. Tem predominado no poder executivo nacional um negacionismo da ciência, gerando contraposições da administração federal a medidas sanitárias sugeridas por organizações de saúde ao redor do mundo e em nosso próprio país. Este quadro de insegurança no que tange às medidas de enfrentamento da crise sanitária vem sendo ampliado no setor de arte e cultura por decisões governamentais equivocadas que prolongam e aprofundam os efeitos da crise.

De fato, no primeiro ano da pandemia ocasionada pelo novo coronavírus, talvez, a maior mobilização em apoio ao setor cultural, a lei Lei no 14.017, de 29 de junho de 2020, carinhosamente chamada de "Lei Aldir Blanc", em homenagem ao compositor vitimado pela Covid, não partiu da Secretaria Especial de Cultura, mas sim da Deputada Federal pelo Rio de Janeiro, Benedita da Silva, que - sendo ligada ao Partido dos Trabalhadores - representa um projeto de poder frontalmente oposto ao atual governo. A lei que destinou três bilhões de reais para socorro ao setor é a principal iniciativa encontrada até o momento, em âmbito nacional, para reduzir a crise no campo artístico e cultural, desta vez, causada pela pandemia.

Com efeito, parece que o Brasil se tornou, portanto, o país em que o termo crise virou sinônimo para um setor que vem agonizando há alguns anos. Assim, os efeitos da Covid-19 se colocam como a pá de cal sobre estrutura já precária. Uma questão já elucidada pela Nota Técnica "O setor cultural na pandemia: O teletrabalho e a Lei Aldir Blanc” (GóEs et al., 2020, p. 18), elaborada por profissionais do IPEA e do IBGE, ao indicar que a informalidade aumentou no setor no período entre 2014-2018. Ou seja, antes mesmo de conhecermos o Sars-CoV-2, o setor já contava com uma estrutura de precarização do trabalho; um fato agravado com a circulação do vírus que força a paralização de atividades que tenham aglomeração, impactando fortemente o setor artístico e cultural. O que se mostra, por exemplo, através da pesquisa "Percepção dos impactos da Covid-19 nos setores cultural e criativo do Brasil", realizada por meio de uma iniciativa que reuniu inúmeras instituições ${ }^{7}$, em que:

7. Aqui nomeadamente: Fórum Nacional de Secretários e Dirigentes Estaduais da Cultura, Secretaria de Estado de Cultura de Alagoas, Secretaria de Estado de Cultura e Economia Criativa do Amazonas, Secretaria de Cultura do Estado da Bahia, Secretaria de Cultura do Estado do Ceará, 
Os participantes responderam sobre os impactos do isolamento social em suas receitas durante os meses de março a julho de 2020 [...]. Entre os meses de março e abril, $41 \%$ dos respondentes perderam a totalidade de suas receitas, e entre maio e julho, essa proporção aumentou para 48,88\%. Em segundo lugar, vêm aqueles que perderam mais da metade de suas receitas $(23,72 \%$ entre março e abril, e $21,34 \%$ entre maio e julho). Somente $17,8 \%$ não tiveram alteração na receita durante março e abril, diminuindo para 10\% nos meses de maio a julho. (AMARAL, FrANCO, LIRA, 2020, p. 10)

Em tempos de pandemia, ao menos no que diz respeito especificamente ao contexto brasileiro, o que se vê, portanto, é o agravamento de uma crise que vem sendo gestada para além do vírus, resultando de ações políticas que vêm há anos sendo tomadas em relação ao setor. A Covid-19 é, nesse sentido, mais uma camada de desestruturação da cultura. Todavia, é fundamental também ressaltar que iniciativas, especialmente em tempos pandêmicos têm buscado garantir a sobrevivência de ações artísticas e culturais no país, para além das demandas ao setor político. O que se nota também nos textos reunidos nesse número temático.

\section{Estratégias de fuga da crise gerada pela Covid-19}

A depressão econômica ocasionada pela necessidade de medidas de restrição de circulação devido à crise sanitária em virtude da Covid-19, como visto, aprofundou problemas precedentes no setor artístico e cultural brasileiro. Além disso, a gestão da crise pela Secretaria Especial de Cultura do governo federal não tem se mostrado eficiente e a única medida pensada para a área tem sido a já referida "Lei Aldir Blanc". Nesse sentido, desesperados ao se verem sem possibilidade de sustento, profissionais do setor de eventos fizeram uma manifestação em setembro de 2020 a fim de cobrar medidas eficientes em seu

Secretaria de Cultura do Estado do Espírito Santo, Secretaria de Cultura do Estado do Pará, Secretaria de Comunicação Social e da Cultura do Paraná, Secretaria de Cultura do Estado de Pernambuco, Representação da UNESCO no Brasil, Serviço Social do Comércio (SESC), Faculdade de Filosofia, Letras e Ciências Humanas da Universidade de São Paulo (FFLCH-USP) e Victor Nunes Toscano. 
socorro $^{8}$. Todavia, o que se vê é ainda o alastramento e aprofundamento da situação de crise.

Com este cenário que hoje nos parece longe de findar - graças à variante do vírus que tem circulado no país e à lentidão na compra e na campanha de vacinação da população -, o ambiente virtual se tornou uma alternativa em busca de saídas para profissionais do campo artístico e cultural, não apenas no Brasil, como vemos através de alguns dos textos trazidos neste número temático.

Em nosso país, algumas atividades têm retomado suas rotinas mediante a realização de testes sorológicos e o uso de EPI's. Filmes, novelas e publicidades, por exemplo, têm sido gravados, ou ainda, alguns museus e salas de cinema retomaram o funcionamento. Contudo, esta não é a realidade para todo o setor e uma boa parcela tem mesmo buscado soluções virtuais. Portanto, embora o cansaço com o isolamento esteja abatendo a população, as medidas de isolamento se mostram necessárias e urgentes, fazendo com que as atividades online sejam as mais indicadas em tempos pandêmicos.

Ainda nos primeiros meses da pandemia, a internet se viu com um boom de toda sorte de eventos culturais, aulas de dança, palestras, shows, peças de teatro, saraus, etc. Enfim, é no ambiente virtual que o campo artístico e cultural tem, de fato, respirado. Muito embora seja comum encontrarmos depoimentos e notícias que indicam que a população já não tem mais conseguido se engajar com força nas atividades virtuais. Os eventos virtuais são foco de alguns textos presentes nesse número temático e indicam a importância do setor artístico e cultural para a manutenção das pessoas em casa. Sem o consumo de arte e cultura seja por meio de livros, peças de teatro, shows, exposições online, seria, de fato, mais difícil o isolamento.

No entanto, também como evidenciam os artigos publicados neste dossiê, a proliferação de lives, canais de streaming e meios de difusão da cultura por meio digital não foi acompanhada pela remuneração do trabalho de artistas no mercado. Estratégias de sobrevivência como monetização de sites e

8. Disponível em: <https://g1.globo.com/sp/sao-paulo/noticia/2020/08/02/tecnicos-de-som-luz-e-imagem-de-eventos-se-manifestam-em-sp-por-protocolos-para-volta-ao-trabalho.ghtml>. Acesso: 03 de mar. 2021. 
estreitamento de redes de solidariedade parecem soluções provisórias para um crescente processo de precarização do trabalho artístico. Redução do público pagante em museus e impedimento de shows e eventos in situ demonstram a fragilidade de uma cadeia econômica que depende de interação social e cujo processo de migração para ambiente virtual exclui setores inteiros da economia criativa. A persistirem os efeitos da pandemia, os polos de criatividade, outrora promissora solução para geração de renda face a processos de desindustrialização, terão de se reconstruir sobre ruínas.

De fato, embora o isolamento social tenha posto em evidência a demanda pela produção de cultura, estas atividades não têm sido, como visto, politicamente valorizadas no caso brasileiro, o que tornou comum a realização de eventos organizados por agentes do setor que buscam angariar recursos a fim de auxiliar colegas de profissão que compõem o que Howard Becker (2008 [1982]) chamou de "mundo da arte", aquele microcosmo social que envolve não apenas artistas, mas toda a cadeia de produção de arte e cultura. Deste modo, se o apoio à redução do Estado tem acompanhado diversos setores da economia brasileira, também, na esfera da produção de cultura, vêm de agentes individuais iniciativas de redução dos danos causados pela pandemia. Assim, aqueles/as/us ${ }^{9}$ que têm na arte e na cultura a sua fonte de sustento, mas não ocupam posições de visibilidade, têm em grande medida contado com doações para o seu sustento e de suas famílias. O que se tem é, portanto, o inverso da valorização da importância que o setor tem ocupado em tempos em que o isolamento é a medida de segurança mais valorizada no que tange à tentativa de preservação da saúde.

\section{Miradas acerca da relação entre arte e pandemia neste número temático}

Tendo as artes em tempos de pandemia de Covid-19 como foco, este número temático recebeu um total de artigos que excede as possibilidades de

9. Como escolha política, utilizamos a linguagem neutra de gênero agregando possibilidades de identificação de gênero que não se enquadram nos padrões políticos de gênero gestados em acordo com a colonialidade, em geral, pautada em padrões binários. Assim, utilizar a linguagem neutra abre espaço para identidades tomadas como desviantes pelo padrão normativo. 
publicação em um único volume; assim, alguns ficaram indicados para publicação em outros números da Revista, à qual temos que agradecer pela abertura a estas discussões. Cabe, ainda, agradecer aos/às/es autores/as/us e pareceristas que somaram conosco nesta empreitada, sem o esforço de quem não teríamos aqui um registro de rotas analíticas acerca da pandemia e seus impactos no campo artístico e cultural. Neste número contamos, portanto, com sete artigos diretamente relacionados ao nosso foco temático; estes textos são de autoria de nove pesquisadores/as vinculados/as a quatro instituições públicas de ensino brasileiras e duas instituições internacionais.

No primeiro artigo, alocado na seção "Temas livres” desta Revista, sob o título "O Saldo da pandemia: perspectivas de mudança para os museus de arte", Glaucia Villas Bôas, professora do Programa de Pós-Graduação em Sociologia e Antropologia da Universidade Federal do Rio de Janeiro e coordenadora do Núcleo de Pesquisa em Sociologia da Cultura na mesma instituição, traz uma discussão sobre os impactos da pandemia para o universo dos museus, especificando a questão no que diz respeito ao Museu de Arte Moderna do Rio de Janeiro (MAM-RJ), ao mesmo tempo em que nos apresenta um panorama internacional por meio de experiências que têm sido implementadas por museus norte-americanos que têm vendido obras de seus acervos em prol de sua sobrevivência. No mesmo caminho, pensando acerca dos museus, Nicole Palucci Marziale, doutoranda no Programa de Pós-Graduação Interunidades em Estética e História da Arte da Universidade de São Paulo (PGEHA - Usp) em "A importância da reafirmação da função social dos museus: antes, durante e depois da pandemia. Perspectivas de mudança?”, verifica o engajamento de diversos museus no auxílio às suas comunidades no enfrentamento da pandemia, reforçando o papel das instituições museais no que diz respeito ao seu contato com a sociedade, na medida em que ele seja efetivo e não apenas figure em menções estanques em textos puramente administrativos.

Sobre as experiências virtuais, os artigos de Pérola Mathias, doutora em Sociologia pelo Programa de Pós-graduação em Sociologia e Antropologia da Universidade Federal do Rio de Janeiro e associada ao Núcleo de Sociologia da Cultura na mesma instituição, e Adan Silva, doutor em Educação e mestre 
em Psicologia pela Universidade Federal do Amazonas, nos trazem múltiplas experiências postas em prática no país. Em "Teresa Cristina: a "rainha das lives" e o mistério do samba 2.0", Mathias se volta ao trabalho efetivado pela proclamada rainha das lives, a cantora Teresa Cristina, buscando compreender sua trajetória que culmina, justamente, em um momento tão crítico em sua coroação como uma personagem fundamental ao enfrentamento aos efeitos negativos do isolamento social. Enquanto isso, trazendo as cirandas realizadas em contexto amazônico, em "Uma experiência nada tradicional", Silva nos fala sobre como a pandemia fez a tradição precisar ser reinventada em um dos estados que mais sofreu com os efeitos da Covid-19. Na sequência, temos o texto de Leonardo Nóbrega, doutor em sociologia pelo Instituto de Estudos Sociais e Políticos da Universidade do Estado do Rio de Janeiro (IEsp/UerJ), professor de sociologia no Instituto Federal de Pernambuco (IFPe) e pesquisador de pós-doutorado do CEBRAP. No artigo intitulado "O mercado editorial brasileiro durante a pandemia de Covid-19", Nóbrega aborda uma crise do mercado editorial que é anterior à ocasionada pela pandemia atual e a partir daí aponta exemplos de como o setor tem se reestruturado para enfrentar as crises que vêm se somando.

Esse número temático conta ainda com a contribuição de Bianca Pires, que é doutora em Sociologia pelo Programa de Pós-graduação em Sociologia e Antropologia da Universidade Federal do Rio de Janeiro e atualmente participante do Seminario sobre Experiencias Cinematográficas no México e no Grupo de Pesquisa de Festivais Audiovisuais, sobre os festivais de cinema que tiveram que migrar para o ambiente virtual, em "La circulación del cine documental en tiempos de pandemia", comparando os contextos brasileiro e mexicano. Também colocando o debate em âmbito internacional, o artigo de Sofia Sousa, mestre em Sociologia pela Universidade do Porto, Paula Guerra, professora no Departamento de Sociologia da Faculdade de Letras da Universidade do Porto e Investigadora Integrada no Instituto de Sociologia da mesma Universidade, e Ana Oliveira, doutoranda em Sociologia na Universidade do Porto, ilustra como os efeitos trágicos da Covid-19 sobre a cultura não são exclusivos do caso brasileiro. Apresentando e discutindo 
impactos da pandemia sobre profissionais da música em Portugal, o artigo "Um requiem pelas músicas que perdemos" coloca em escala global, os efeitos das estratégias individuais dos agentes ligados ao setor.

Esperamos que esse número temático possa contribuir para as análises acerca dos efeitos da pandemia no setor artístico e cultural, não apenas no que diz respeito ao contexto brasileiro. Além disso, aproveitamos para saldar profissionais do setor que têm se desdobrado em prol de sua sobrevivência, esperando que arte e cultura deixem de ser sinônimo de crise no Brasil. \#vacinasim \#culturaviva

\section{Guilherme Marcondes (PPGS-UECE) ${ }^{10}$ Sabrina Parracho Sant'anna (UFRRJ) ${ }^{11}$}

\section{Referências}

AMARAL, Rodrigo Correia do; FRANCO, Pedro Affonso Ivo; LIRA, André Luís Gomes. Pesquisa de percepção dos impactos da COVID-19 nos setores cultural e criativo do Brasil. Paris/ Brasília: Organização das Nações Unidas para a Educação, a Ciência e a Cultura - UNESCO, 2020. Disponível em: <https:// datastudio.google.com/u/0/reporting/88bf6daa-3f58-4f5a-bb3f-9d4f5c3dc73b/ page/FdCXB?s=lhRljARPY8E $>$. Acesso em 03 de mar. 2021.

BARBALHO, Alexandre. Política Cultural em Tempo de Crise: o Ministério da Cultura no Governo Temer. Maranhão: Revista de Políticas Públicas da UFMA, v. 22, p. 239-260, 2018.

BECKER, Howard S. Art worlds. Berkeley: University of California Press, [1982] 2008.

10. Pós-doutorando (com bolsa PNPD/CAPES) no Programa de Pós-Graduação em Sociologia da Universidade Estadual do Ceará (PPGS-UECE). Doutor e mestre pelo Programa de Pós-Graduação em Sociologia e Antropologia da Universidade Federal do Rio de Janeiro (PPGSA-UFRJ). Orcid: 00000001-6114-7944. E-mail: gui.marcondesss@gmail.com

11. Professora associada do Departamento de Ciências Sociais da Universidade Federal Rural do Rio de Janeiro (UFRRJ) e professora permanente do Programa de Pós-Graduação em Ciências Sociais da mesma instituição. Doutora e mestre pelo Programa de Pós-Graduação em Sociologia e Antropologia da Universidade Federal do Rio de Janeiro (PPGSA-UFRJ). Em 2019, concluiu pós-doutorado na Universitat de Barcelona (Espanha). Orcid: 0000-0003-1726-2018. E-mail: saparracho@gmail.com 
BUENO, Maria Lucia; SANT'ANNA, Sabrina M. P.; DABUL, Ligia. Sociologia da Arte: breve histórico da construção de uma disciplina. Revista Brasileira de Sociologia, v. 6, p. 266-289, 2018.

DURÃO, Mariana. País deixa grupo das dez maiores economias. O Estado de São Paulo. 04/03/2021. Disponível em: <https://economia.estadao.com.br/noticias/ geral,brasil-deixa-ranking-das-10-maiores-economias-apos-queda-de-4-1-dopib,70003634630>. Acesso: 28 de mar. 2021.

GÓES, Geraldo; ATHIAS, Leonardo Q.; MARTINS, Felipe S.; SILVA, Frederico A. B.. O setor cultural na pandemia: O teletrabalho e a Lei Aldir Blanc. 2020. Disponível em: <https://www.ipea.gov.br/portal/images/stories/PDFs/conjuntura/201015_ cc49_cultura.pdf $>$. Acesso em 03 de mar. 2021.

IBGE. Painel de indicadores. Disponível em: <https://www.ibge.gov.br/ indicadores>. Acesso: 28 de mar. 2021.

. Principais destaques da evolução do mercado de trabalho no Brasil 20122020. Pesquisa Nacional por Amostra de Domicílios Contínua. Disponível em: https://ftp.ibge.gov.br/Trabalho_e_Rendimento/Pesquisa_Nacional_por_Amostra_ de_Domicilios_continua/Principais_destaques_PNAD_continua/2012_2020/ PNAD_continua_retrospectiva_2012_2020.pdf. Acesso: 28 de mar. 2021.

QUIJANO, Aníbal. Colonialidade do Poder e Classificação Social. In: SANTOS, Boaventura de Sousa; MENESES, Maria Paula (Orgs.). Epistemologias do Sul. Coimbra: Edição Almedina, 2009.

REIS, Vivian. Técnicos de som, luz e imagem de eventos se manifestam em SP por protocolos para volta ao trabalho. São Paulo: G1. Disponível em: < https:// g1.globo.com/sp/sao-paulo/noticia/2020/08/02/tecnicos-de-som-luz-e-imagemde-eventos-se-manifestam-em-sp-por-protocolos-para-volta-ao-trabalho.ghtml>. Acesso: 03 de mar. 2021.

SANT'ANNA, Sabrina M. P.; MARCONDES, Guilherme; MIRANDA, Ana Carolina F. A. Arte e política: a consolidação da arte como agente na esfera pública. Rio de Janeiro: Revista Sociologia \& Antropologia, v. 7, p. 825-849, 2017.

WORLDOMETER. Covid-19. <https://www.worldometers.info/coronavirus/country/ brazil/>. Acesso: 28 de mar. 2021. 